\title{
Zbuntowana hiperseksowność: demontaż męskiej popkultury według Peaches
}

\section{Sławomir KUŹNICKI}

\begin{abstract}
Streszczenie
Peaches (Merrill Beth Nisker) to jedna z najbardziej kontrowersyjnych postaci popkultury XXI wieku. Główny nurt twórczości tej kanadyjskiej artystki, działającej w ramach szeroko rozumianej kultury muzyki rockowej, to wyrażony poprzez seksualność bunt przeciwko zakorzenionej w patriarchacie hipokryzji współczesnych struktur władzy, które nadal dominują relacje międzyludzkie i popkulturę. W swoich działaniach artystycznych - głównie w tekstach piosenek - Peaches odgrywa szereg seksualnych transgresji, których zadaniem jest wyrażenie sprzeciwu wobec ograniczeń wolności, tożsamości i równości. Stara się demontować istniejący od lat i przestarzały system wartości, swoim podstawowym orężem czyniąc dosadne i szokujące traktowanie seksualności, którą nazywam hiperseksownością (wywodząc tę kategorię od zaproponowanej przez Amy Shields Dobson koncepcji heteroseksowności). Niniejszy artykuł jest próbą odczytania bezkompromisowej i buntowniczej postawy Peaches wobec zdominowanej przez męski punkt widzenia popkultury, przy pomocy wspomnianej wyżej kategorii hiperseksowności.
\end{abstract}

Słowa kluczowe: Peaches, hiperseksowność, muzyka rockowa, seksualności, patriarchat, transgresja

Sławomir KUźNICKI doktor nauk humanistycznych w dziedzinie literaturoznawstwa, adiunkt w Instytucie Nauk o Literaturze Uniwersytetu Opolskiego, autor monografii Margaret Atwood's Dystopian Fiction: The Fire Is Being Eaten (2017) oraz licznych artykułów naukowych, w których zajmuje się dystopiami, science fiction, feminizmami i kulturą muzyki rockowej; redaktor w „Explorations: A Journal of Language and Literature"; poeta z dorobkiem czterech tomików wierszy (ostatni - Kontury, 2018).

E-MAIL: slavekkk@wp.pl 
Merrill Beth Nisker, lepiej znana pod scenicznym pseudonimem Peaches, to kanadyjska wokalistka i artystka performatywna, obecnie działająca głównie w Europie. Jej twórczość stanowi doskonały przykład przeciwstawiania się stale obecnemu w naszych czasach męskiemu spojrzeniu, którego celem jest uprzedmiotowienie kobiecego ciała. Co więcej, w czasach postfeminizmu Peaches asymiluje męski seksizm, by - w świadomie wyolbrzymionej formie - uczynić z niego istotny element swojej własnej „heteroseksownej”, jak powiedziałaby Amy Shields Dobson (Dobson 2014, 40), czy wręcz „hiperseksownej” tożsamości. Szokująco szczery stosunek do własnej seksualności stanowi dla Peaches podstawową broń w jej buncie przeciwko zakorzenionej w patriarchacie hipokryzji współczesnych struktur władzy, które nadal dominują relacje międzyludzkie i popkulturę. Lorraine Carpenter opisuje jej strategię w następujący sposób: „Jest pożeraczką kobiet (i mężczyzn), elektryzującą nimfomanką elektro rocka, fontanną płynnych seksualności. Jest albo chodzącą gwiazdą porno, albo zwiewną feministką; superhermafrodytą, kobietą, mężczyzną" (Carpenter 2003) ${ }^{1}$.

\section{My name is Peaches. Rys biograficzny}

Merrill Beth Nisker urodziła się w kanadyjskim Toronto w 1968 roku, w żydowskiej rodzinie pochodzenia polsko-ukraińskiego (Mullen 2015). W Kanadzie spędziła pierwsze trzydzieści lat swojego życia, studiując teatrologię na Uniwersytecie York, a potem prowadząc zajęcia teoretyczno-praktyczne z muzyki i teatru w prywatnych szkołach; oba te doświadczenia wpłyną na jej późniejsze strategie artystyczne. Carpenter zauważa: „W latach dziewięćdziesiątych Nisker opracowała program edukacyjny dla dzieci pomiędzy trzecim, a szóstym rokiem życia, wprowadzający je w świat sztuki. Wykorzystała ten czas do obserwacji naturalnej spontaniczności i wrodzonej szczerości, jakimi dzieci się cechują. Obie te wartości - przetworzone przez jej doświadczenia dorosłości - wpłynęły później na uformowanie postaci Peaches” (Carpenter 2003) ${ }^{2}$. Choć już w tamtym czasie Nisker występowała w amatorskim

${ }^{1}$ Przekład własny za: „She's a man-eater (and a woman-eater too), a high voltage electro-rock nympho on record and a gender-fucking sexual conduit on stage. She's either a walking porno or a frothy feminist, a herm hero, a woman, a man".

2 Przekład własny za: „In the 9os, Nisker developed an introductory arts program for threeto-six-year-olds. She took the opportunity to observe children's natural spontaneity and innate honesty, qualities she later employed as Peaches, in her own, adult way". 
trio folkowym o nazwie Mermaid Café, za właściwy początek jej kariery muzycznej uznać należy rok 1995, kiedy to artystka opublikowała swój pierwszy album Fancypants hoodlum, zawierający interesującą mieszankę jazzu, pun$\mathrm{ku}$ i indie rocka. Płyta ta sygnowana była jej prawdziwym nazwiskiem, ale jeszcze w tym samym roku, już pod pseudonimem, wraz z przyjaciółmi wśród nich znalazł się między innymi Jason Beck, znany później jako Chilly Gonzales - Peaches założyła kwartet The Shit, grający no-wave'owego rocka (po kilku miesiącach zespół zmienił nazwę na Freedom i zaprezentował się w bardziej hardrockowym repertuarze). Pseudonim Niskier zaczerpnęła ze słynnego standardu Niny Simone Four women z 1966 roku. Na jej decyzję wpłynęła szczególnie ostatnia część piosenki, w której Simone tworzy postać zbuntowanej, odrzucającej niewolnicze dziedzictwo młodej kobiety; deklaracja, podkreślana przez pełne napięcia i emocji ostatnie wersy pieśni: „Moja skóra ma brązowy kolor, / z natury jestem twarda. / Ostatnio bywam też gorzka. / Wiesz jak mnie nazywają? / Moje imię to Peaches!” (Simone 1966)3 . Peaches wspomina: „Chciałam, żeby ona [Simone] śpiewała te słowa do mnie, więc tak właśnie się nazwałam” (Rosenblum 2013)4. Tym samym, Kanadyjka niejako powtórzyła gest swojej wielkiej idolki (w połowie lat pięćdziesiątych Eunice Kathleen Waymon przybrała pseudonim Nina Simone) i narodziła się na nowo. Drugim momentem krytycznym w procesie formowania się artystycznej persony Niskier była, podjęta pod koniec dwudziestego wieku przez wszystkich członków The Shit / Freedom, decyzja o przenosinach do Niemiec (Carpenter 2003).

Prawdziwym debiutem fonograficznym Peaches jest minialbum Lovertits, wydany w 2000 roku, oraz pierwsza płyta długogrająca, zatytułowana The teaches of Peaches, która ukazała się kilka miesięcy później. Muzyka Peaches z tego okresu to hybryda elektroniki z elementami rocka, zdominowana przez dźwięki syntezatora Roland MC-505. The teaches of Peaches zawiera jedne z najbardziej znanych piosenek Peaches, takie jak Fuck the pain away, czy zilustrowana kontrowersyjnym teledyskiem, zakazanym w większości amerykańskich telewizji Set it off. Na drugiej płycie artystki - Fatherfucker (2003) - znalazła się najbardziej jednoznacznie rockowa muzyka w całej jej dotychczasowej karierze. Album jest słynny ze względu na niejednoznaczną płciowo okładkę ze zdjęciem wokalistki z brodą, a znaleźć na

3 Przekład własny za: „My skin is brown / my manner is tough / I’m awfully bitter these days / What do they call me? / My name is Peaches!”.

4 Przekład własny za: „I wanted her to be singing this to me so I took on that name”. 
nim można chociażby jej duet z ikoną niezależnej muzyki rockowej, Iggym Popem. Dyskografię Peaches uzupełniają trzy kolejne płyty długogrające: Impeach my bush (2006), którą artystka promowała serią koncertów z udziałem kobiecej grupy akompaniującej The Herms, I feel cream (2009) oraz Rub (2015). Na wszystkich tych płytach Peaches prezentuje swoją autorską wersję muzyki elektronicznej, raz tanecznej, kiedy indziej bardziej rockowej, zawsze zdecydowanie alternatywnej. Na każdej z nich artystka proponuje kolejne duety z przedstawicielami rocka i muzyki pop, takimi jak: Joan Jett, Beth Ditto, Feist (niegdyś współlokatorka Peaches), Josh Homme, Simian Mobile Disco, czy Kim Gordon. Jednocześnie Peaches sama pojawia się na płytach innych wykonawców, a na tej długiej i stale się powiększającej liście znaleźć można takie nazwiska i zespoły, jak: Chilly Gonzales, Chicks on Speed, Iggy Pop, Pink, Karen O, Christina Aguilera, R.E.M., czy Jean-Michel Jarre.

Jednakże w swojej działalności artystycznej Peaches nie ogranicza się tylko do muzyki. Na przykład w 2010 roku, we współpracy z berlińskim teatrem Hebbel am Ufer, stworzyła własną wersję słynnego musicalu Tima Rice’a i Andrew Webbera, Jesus Christ Superstar. W serii performance'ów zatytułowanych Peaches Christ Superstar wystąpiła tylko ona oraz towarzyszący jej na fortepianie Chilly Gonzales. Oprócz tego, Peaches spróbowała swoich sił w przemyśle filmowym. Poza zagraniem pomniejszych ról w kilku obrazach, w 2012 roku wyprodukowała film Peaches does herself, który można określić mianem autobiograficznej elektro-rockowej opery, jako że zawiera aż dwadzieścia dwie piosenki z jej repertuaru. W końcu, zaproszona przez Yoko Ono na londyński Meltdown Festival, Peaches odegrała słynny performance Japonki z połowy lat sześćdziesiątych, zatytułowany Cut piece ${ }^{5}$. Tym razem widzowie mieli za zadanie odcinanie fragmentów jej ubrania, podczas gdy ona - wzorem swojej wielkiej prekursorki - siedziała milcząco na środku sceny (Mullen 2015). Peaches mówi: „Nieustannie staję się sobą, a dokonuję tego poprzez wyzwania artystyczne" (Rosenblum 2013) .

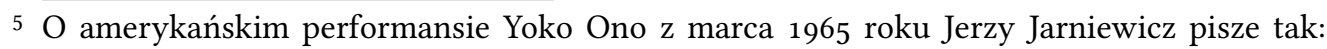
„Yoko Ono weszła na scenę ubrana w ściśle przylegającą do ciała czarną sukienkę z długimi rękawami. W ręku trzymała nożyczki. Usiadła na scenie, skuliwszy nogi, nożyczki położyła przed sobą. Zaprosiła obecnych, by podchodzili do niej i wycinali kawałki jej ubrania. Na zaproszenie odpowiedzieli i mężczyźni, i kobiety. [...] Odcinanie kolejnych kawałków jej ubrania, bez względu na to, czy odbywało się delikatnie, czy z natarczywością, wiązało się z możliwym cierpieniem, zadanym nieopatrznie, przypadkowo, lub, przeciwnie, intencjonalnie. Było też aktem podszytym seksualną przemocą, która w każdej chwili mogła się ziścić” (Jarniewicz 2019, 153-154).

6 Przekład własny za: „I am constantly becoming myself and I do this through my artistic challenges". 
Działalność artystyczna Peaches jest nierozerwalnie powiązana z jej wizerunkiem publicznym. Na scenie, oraz w różnego rodzaju mediach, artystka jest dosadnie wyzywająca, żeby nie powiedzieć pornograficzna. Bezpośredniość i bezpruderyjność, jakie cechują jej występy czy teledyski, są jednocześnie pełne ironii i pastiszu. Peaches dobrze czuje się w estetyce kampu, która jest jej w oczywisty sposób bliska. Jednak tym, co najważniejsze w wyzwaniach artystycznych Peaches, pozostaje muzyka oraz towarzyszące jej teksty, w których Kanadyjka realizuje własną wizję „postgenderowej” hiperseksowności (Mullen 2015). A robi to w obrębie kultury rocka, czyli takiego rodzaju kultury, który „jest zdefiniowany przez płeć kulturową, i to zarówno w regresywny, jak i progresywny sposób” (Kearney 2017, xvi-xvii)7. Tym samym, przed skupieniem się na działalności artystycznej samej Peaches, rzeczą absolutnie konieczną wydaje się nakreślenie owego tła kulturowego i zestawienie go z szeroko rozumianą polityką płciowości.

\section{It's a Man's Man's Man's World. Kobiety w świecie rocka}

W ujęciu tradycyjnym, rock jest tym kulturowo-społecznym terytorium, które zostało zdominowane przez mężczyzn i ich punkt widzenia. Mary Celeste Kearney zauważa: „W kulturze rocka istnieje wiele ideologii. Ale to patriarchat wydaje się tą najbardziej dominującą, i to pomimo szerokiego wpływu feminizmu oraz coraz większej liczby kobiet-muzyków, które pojawiły się w ostatnim półwieczu" (Kearney 2017, 11) ${ }^{8}$. Doskonałym przykładem jest tu anglojęzyczna kategoria cock rock $a^{9}$, w kulturze anglosaskiej stosowana zazwyczaj wymiennie $\mathrm{z}$ blues rockiem $\mathrm{i}$ hard rockiem przełomu lat sześćdziesiątych i siedemdziesiątych XX wieku, jako że w obu tych podgatunkach zaobserwować można „uprzywilejowaną pozycję fallocentrycznej męskości, zarówno w tekstach piosenek, jak i w sposobie występowania”

7 Przekład własny za: „defined by gender in both regressive and progressive ways”.

8 Przekład własny za: „Many ideologies exist in rock culture. Yet patriarchy has been one of its most dominant ideologies, despite the broad influence of feminism and the increasing number of women musicians over the past half century".

9 W polskiej nomenklaturze fraza ta nie ma swojego odpowiednika. Być może należałoby ją przetłumaczyć jako „rock koguci”; nie należy przy tym zapominać, że słowo cock to też wulgarne określenie penisa. 
$\left(\right.$ Kearney 2017, 97 ${ }^{10}$. Jednocześnie, cock rock funkcjonuje również jako wspólny dla wszystkich gatunków rocka zdominowanych przez mężczyzn, używających gitary elektrycznej jako „narzędzia fallicznego” (Kearney 2017, 141) ${ }^{11}$, czyli w sposób symboliczny, który „stanowi łącznik pomiędzy muzycznymi umiejętnościami (części rockowych gitarzystów) a ich sprawnością seksualną - albo poprzez pseudomasturbacyjne zachowanie, albo przez pocieranie gitary, jakby była ona kobietą" (Kearney 2017, 141-142) ${ }^{12}$. W piosence Rock show Peaches w ironiczny sposób komentuje tę sytuację. Na tle hardrockowego riffu przesterowanej gitary śpiewa: „Przyszliście zobaczyć rockowe show / Wielkie, gigantyczne kogucie show / Chcecie zobaczyć to wszystko" (Peaches 2000) ${ }^{13}$.

Przez lata jedyną oficjalnie akceptowaną rolą kobiety w zdominowanym przez mężczyzn świecie rocka była pozycja wokalistki. Z jednej strony wynikało to z rzekomej niezdolności kobiet do obsługi technologii, a tym samym braku umiejętności niezbędnych do grania na jakimkolwiek instrumencie $\mathrm{w}$ wirtuozerski sposób kojarzony z mężczyznami. Z drugiej, ta dysproporcja między wokalistkami a kobietami-muzykami wiązała się bezpośrednio z patriarchalną polityką uprzedmiotowienia kobiet jako obiektów męskiego pożądania. Kearney: „łącząc kobiecy występ z kobiecą heteroseksualnością, rola wokalistki zachowuje status quo. Tym samym wokalistki zazwyczaj wciąż uosabiają bierny i seksualny obiekt czynnego spojrzenia mężczyzn” (Kearney 2017, 120) ${ }^{14}$. Jak zauważa Germaine Greer w słynnym Kobiecym eunuchu: „Stereotyp to Wieczna Kobiecość. To Obiekt Seksualny, upragniony i poszukiwany przez każdego mężczyznę i wszystkie kobiety. Nie ma płci. Jego wartość mierzy się wyłącznie pożądaniem, które wyzwala w innych. Jedynym, co musi wnosić, jest samo istnienie” (Greer 2001, 55). Koncepcje te współgrają z bardziej uniwersalnymi rozważaniami Gayle S. Rubin na temat seksualnych norm istniejących w świecie popkultury:

${ }^{10}$ Przekład własny za: „overprivileging phallic masculinity in lyrics and performance styles”.

${ }^{11}$ Przekład własny za: „as a phallic device”.

${ }^{12}$ Przekład własny za: „that conflates [some male rock guitarists'] musical skills with their sexual skills, either via pseudomasturbatory behavior or stroking the guitar as if it were a woman".

${ }^{13}$ Przekład własny za: „You came to see a rock show / A big gigantic cockshow / You came to see it all”.

${ }^{14}$ Przekład własny za: „by connecting female performance with heterosexual feminine gender display, the role of the vocalist allows the status quo to be maintained. Thus, women vocalists are still typically constructed as the passive, sexualized objects of men's active gaze". 
Kultura popularna przeniknięta jest założeniem, że różnorodność erotyczna jest czymś niebezpiecznym, niezdrowym, zdeprawowanym i stanowiącym zagrożenie dla wszystkiego, począwszy od małych dzieci, a skończywszy na bezpieczeństwie narodowym. Popularna ideologia seksualna jest szkodliwą mieszanką, na którą składają się idea cielesnego grzechu, koncepcje psychologicznej niższości, anty-komunizm, histeria tłumu, oskarżenia o czary i ksenofobia. Media masowe napędzają takie zapatrywania przy pomocy niepohamowanej propagandy. Nazywam ów system erotycznego stygmatu ostatnią społecznie respektowaną formą uprzedzeń. (Rubin 2007, 152) ${ }^{15}$

Koncepcje te, mimo iż wywodzące się z dekad poprzedzających działalność Peaches, okazują się stale aktualne w kontekście jej działalności. Pomimo, że historia rocka zna niejedną wokalistkę walczącą ze wspomnianym powyżej stereotypem, wydaje się, że najlepszym sposobem na przełamanie erotycznego stygmatu, o którym pisze Rubin, na „zdystansowanie się od marginalizowanej i sfeminizowanej roli wokalistki” (Kearney 2017, 122) ${ }^{16}$, było $\mathrm{i}$ jest zaangażowanie się w grę na instrumentach i perfekcyjne opanowanie tej tradycyjnie męskiej umiejętności.

W przypadku wielu artystek muzyki rockowej rozwiązaniem jest łączenie rocka z dźwiękami generowanymi elektronicznie oraz z tekstami o charakterze feministycznym. Sprawdza się to idealnie w odniesieniu do Peaches, której „bronią stał się syntezator Roland MC-505, nazywany przez nią samą jej zespołem MC5" (Carpenter 2003) ${ }^{17}$, jak też słowa, o których artystka mówi, że są „postgenderową i postage'ową celebracją stawania się tym, kim jesteśmy” (Azzopardi 2015) ${ }^{18}$. W szerszym ujęciu, Kearney zwraca uwagę na to, że „nie jest zaskoczeniem, iż niektóre kobiety związane z elektronicznym rockiem wyrażają swoje feministyczne przekonania zarówno poprzez słowa piosenek, jak i wywiady, jednocześnie składając hołd tym kobietom grającym na instrumentach elektronicznych, które utorowały im drogę"

\footnotetext{
15 Przekład własny za: „Popular culture is permeated with ideas that erotic variety is dangerous, unhealthy, depraved, and a menace to everything from small children to national security. Popular sexual ideology is a noxious stew made up of ideas of sexual sin, concepts of psychological inferiority, anti-communism, mob hysteria, accusations of witchcraft, and xenophobia. The mass media nourish these attitudes with relentless propaganda. I would call this system of erotic stigma the last socially respectable form of prejudice".

${ }^{16}$ Przekład własny za: „distance [themselves] from the marginalized and feminized position of vocalists".

${ }^{17}$ Przekład własny za: „weapon of choice was a Roland MC-505, which she calls her MC5”.

${ }^{18}$ Przekład własny za: ,a post-gender and post-age celebration of becoming who you are”.
} 
$(\text { Kearney } 2017,105)^{19}$. Tym samym dla Peaches, jak i dla wielu innych artystek kultury rocka, elektropunk - bo tak należałoby nazwać ową fuzję muzyki elektronicznej z agresywnym rockiem - stanowi fundament, na którym Kanadyjka tworzy i odgrywa swoją nieustannie płynną i wymykającą się tożsamość. Jednak obraz twórczości Peaches byłby niepełny bez bezpośrednich i niedwuznacznych odniesień do strefy seksualnej, którą artystka traktuje jako otwarte terytorium, przemierzając je, w którą tylko stronę ma ochotę. Carpenter zauważa: „Peaches krzyczy seksem, wypluwa z siebie rock'n'rolla i zarzuca na nas hip-hopowe rymy. Jest szczerą, propagującą równe szanse dostarczycielką rozrywki, skurwielką i filozofką" (Carpenter 2003) ${ }^{20}$. Aby zrozumieć Peaches i jej sztukę, proponuję odczytanie jej strategii artystycznych poprzez wspomnianą już powyżej kategorię hiperseksowności.

\section{I'm too sexy. Koncepcja hiperseksowności}

Postać, którą Peaches tworzy i odgrywa, zarówno w swoich tekstach, jak i ich wizualnej reprezentacji (okładki płyt, teledyski, wizerunek sceniczny etc.), doskonale pasuje do koncepcji hiperseksowności. Jednak, aby zrozumieć, czym hiperseksowność jest, należy odnieść ją do koncepcji heteroseksowności zaproponowanej przez Amy Shields Dobson w książce Postfeminist digital cultures. Koncentrując się na współczesnej medialnej reprezentacji dziewczyn i kobiet, Dobson widzi w heteroseksowności najbardziej powszechny sposób na realizację ich kobiecości:

Heteroseksowność nie jest stała, ciągle się zmienia; jest też kulturowo uwarunkowana. Można by wręcz zasugerować, że jest ważnym punktem odniesienia dla dziewczyn i kobiet anglojęzycznego zachodu. Jest estetyczną pochodną zarówno tradycyjnej kobiecości (róż, delikatność, ozdobność, pretensjonalność etc.), jak i mainstreamowej, heteroseksualnej pornografii (nienaturalnie powiększone sztuczne piersi, wysokie obcasy, przesadny makijaż, ubrania odsłaniające ciało i zwracające uwagę na sfery erogenne). (Dobson 2015, 40) $)^{21}$

${ }^{19}$ Przekład własny za: „it is no surprise that some women associated with electronic rock have voiced their feminist values in both lyrics and interviews, while also paying their respects to the female electronic musicians who came before them".

${ }^{20}$ Przekład własny za: „Peaches screams sex, shouts rock'n'roll and drops hip-hop rhymes. She's an honest, equal opportunity entertainer, fucker and philosopher”.

${ }^{21}$ Przekład własny za: „Heterosexiness is constantly changing rather than static, and it is culturally specific. We might in brief suggest that it is currently constituted in the Anglophone 
Projekt ten łączy w sobie cechy afirmatywne i kontestujące, gdyż, podkreślając kobiecość, czyni to w odniesieniu do męskich oczekiwań. Dlatego heteroseksowność może stać się pułapką dla kobiet, które chciałyby traktować ją jako pełną realizację ich kobiecości, ponieważ koncepcja ta nadal opiera się na nierównej dystrybucji władzy pomiędzy płciami. W końcu heteroseksowność zdaje się dotyczyć tylko dwu płci - kobiet i mężczyzn, ograniczając siłę swojego oddziaływania do takiego normatywnego i przestarzałego podziału. A przecież, jak zauważa Gayle Rubin: „system seksualny nie jest strukturą monolityczną i wszechwładną" (Rubin 2007, 161) 22. Stąd potrzeba kategorii zdolnej pomieścić wszystkie niuanse współczesnych i płynnych seksualności, kategorii, która pozwoli na zrozumienie Peaches wraz z jej seksualnymi transgresjami.

Hiperseksowność jest, w moim odczytaniu, rozszerzoną wersją heteroseksowności, głównie dlatego, że jest kategorią zdecydowanie bardziej otwartą na płynną różnorodność ludzkich seksualności. W tym sensie jest więc również realizacją następujących słów Rubin:

Większości ludzi trudno jest zrozumieć, że coś co lubią robić w sferze swojej seksualności, jest całkowicie odrażające dla kogoś innego, oraz że coś co odpycha ich seksualnie, jest zarazem najbardziej cenione przez innych. [...] Większość ludzi myli swoje własne preferencje seksualne z jakimś uniwersalnym systemem, który powinien obowiązywać wszystkich. (Rubin 2007, $154)^{23}$

Niejako w odpowiedzi na te słowa, hiperseksowność wykracza poza moralność, a przynajmniej poza moralność rozumianą jako jedna konkretna ideologia reprezentowana przez daną społeczność. Hiperseksowność akcentuje też fizyczność doświadczenia seksualnego oraz wpisane weń pożądanie cielesne. Dobson zauważa: „w postfeministycznych czasach kobiecość bardziej

West for girls and women as an aesthetic derivative of both traditional femininity (pink, delicate, decorative, cutesy, and so on) and mainstream heterosexual pornography (overly large artificial looking breasts, high heels, excessive makeup, flesh-revealing clothing and clothing which draws attention to sexual and erogenous zones)".

${ }^{22}$ Przekład własny za: „the sexual system is not a monolithic, omnipotent structure”.

${ }^{23}$ Przekład własny za: „Most people find it difficult to grasp that whatever they like to do sexually will be thoroughly repulsive to someone else, and that whatever repels them sexually will be the most treasured delight of someone, somewhere. [...] Most people mistake their sexual preferences for a universal system that will or should work for everyone". 
koncentruje się na ciele i seksowności, jako swoich cechach charakterystycznych" (Dobson 2014, 32) 24. Idąc dalej tym tropem, można odczytać hiperseksowność jako ostateczną realizację postulatu sformułowanego lata wcześniej przez Germaine Greer. Reinterpretując zasadę przyjemności Freuda i podkreślając jej znaczenie w procesie kobiecej emancypacji, pisarka stwierdza: „Główną zasadą w wyzwoleniu kobiet jest zastąpienie przymusu i braku wyboru zasadą przyjemności [...]. Kwintesencją przyjemności jest spontaniczność. W tym wypadku spontaniczność oznacza odrzucenie normy, standardu i określenie samoregulującej się zasady" (Greer 2001, 368). Taka postawa jest czymś, czego Peaches wydaje się być w pełni świadoma: jej projekty artystyczne zawierają w sobie spore ilości ironii, czy też autoironii, i figlarności, czyli czystej, nieskażonej radości, która odziera seks i seksualność z aury sekretności i obsceniczności. Rubin zauważa: „Seksualność jest w takiej samej mierze produktem człowieka, jak diety, środki transportu, konwenanse, rodzaje zatrudnienia, gatunki rozrywki, procesy produkcji, czy formy opresji” (Rubin 2007, 149) 25. Peaches nie tylko to rozumie, ale też wprowadza te zasady w świat kultury popularnej i robi to w sposób jak najbardziej ironiczny.

\section{Lust for life. Upodmiotowienie pożądania}

Odmiana hiperseksowności, którą Peaches wyraża w swojej sztuce, jest mocno związana ze swawolnością, z jaką podchodzi do swojego ciała, jak też innych ciał, z którymi wchodzi w interakcje. Koncentruje się na własnym, całkowicie kobiecym pożądaniu i fizycznej seksualności. Jak mówi: „Chodzi o bycie otwartym, tak, aby każdy mógł stać się tym, kim jest, w zgodzie ze swoim ciałem. Robimy różne rzeczy, żeby uciec od swoich ciał, ale przecież to w nich żyjemy" (Azzopardi 2015) ${ }^{26}$. Tym samym Peaches podważa patriarchalne założenie, jakoby cielesna żądza miała stanowić domenę mężczyzn. Jak krytycznie stwierdza Rubin: „Częścią współczesnej ideologii seksu jest założenie, jakoby pożądanie było domeną mężczyzn, a czystość -

${ }^{24}$ Przekład własny za: „in the postfeminist era, femininity has become more focused on the body and on hotness as a key characteristic of femininity”.

${ }^{25}$ Przekład własny za: „Sexuality is as much a human product as are diets, methods of transportation, systems of etiquette, forms of labour, types of entertainment, processes of production, and modes of oppression".

${ }^{26}$ Przekład własny za: „It’s about being open so that everybody can actually become the person they are and feel comfortable in their own bodies. We do all these things to get away from our own bodies, but we live in them". 
kobiet. Nie jest przypadkiem, że pornografia i perwersje przez lata były uważane za przynależne mężczyznom" (Rubin 20017,170$)^{27}$. Peaches odmawia bycia cnotliwą i niewinną, jej świat to świat seksualnej dosłowności i ekscesu. W jednej ze swoich najbardziej znanych piosenek - Fuck the pain away - deklaruje:

Ssiesz moje cycuszki tak jak zawsze chciałeś

Cały czas nazywasz mnie blondynką

A jak nie patrzę gapisz się na inne

I w porządku, nie ma problemu

Tak jak z seksem na plaży

Bo cóż innego jest w naukach Peaches?

No co? No co?

$(\text { Peaches 2000 })^{28}$

Igrając zarówno ze stereotypowymi normami tradycyjnych społeczeństw, jak i z kontekstami kultury rocka (nieprzetłumaczalne na język polski nawiązanie do nowofalowego zespołu Blondie dowodzonego przez charyzmatyczną Debbie Harry), Peaches bez zahamowań mówi o swoich potrzebach seksualnych.

W dążeniu do tego celu Peaches nie jest ani sentymentalna, ani delikatna. Zamiast tego otwarcie werbalizuje swoje pragnienia, co stoi w oczywistej sprzeczności z tradycyjną, sformułowaną przez mężczyzn kobiecością. W piosence Hot rod wkracza do świata zwyczajowo zarezerwowanego dla mężczyzn, świata prawie pornograficznej obsceniczności:

Podoba ci się, kiedy lubię cię mniej

Żadnych pieszczot, od razu akcja

Lubisz kiedy gramy ostro

Wojna na figi, kici w bród

Lubisz kiedy jestem z tyłu

Kiedy nie daję ci wytchnienia, nawet na sekundę

Lubisz kiedy nie ma czasu na zdjęcie wszystkiego

${ }^{27}$ Przekład własny za: „Part of the modern ideology of sex is that lust is the province of men, purity that of women. It is no accident that pornography and perversions have been considered part of the male domain".

${ }^{28}$ Przekład własny za: „Sucking on my titties like you wanted me / Calling me, all the time like Blondie / Check out my chrissy behind / It's fine all of the time / Like sex on the beaches / What else is in the teaches of Peaches? / Huh? What?". 


\section{A my wchodzimy na wysokie obroty \\ Coraz wyższe i wyższe.}

$(\text { Peaches 2000 })^{29}$

Taki bezpruderyjny stosunek do seksu pokazuje też wielką pewność siebie, z jaką Peaches traktuje swoich potencjalnych partnerów i partnerki erotyczne. Odrzuca pasywne zachowanie tradycyjnie zarezerwowane dla kobiet, żeby przyjąć postawę hiperaktywną. Jak tryumfalnie stwierdza: „Ja. Jestem. Tą. Która. Cię. Weźmie” (Peaches 2006) ${ }^{30}$. Jej podejście współgra ze zmianami dostrzeżonymi przez Amy Shields Dobson w świecie mediów wizualnych:

Robiące wrażenie obrazy kobiecych ciał, które są „aktywne”, a nie pasywne, które są pożądane i pożądają, stają się dziś powszechne w pejzażu internetowym i w pewnych konkretnych sektorach kultury [...]. Zmiany te komplikują binarną opozycję przedmiot/podmiot, jako że kobiety są przedstawiane jako czynne uczestniczki procesu uprzedmiotowienia, czy raczej seksualnego upodmiotowienia, które z kolei nadal zasadza się na dużej ilości zdyscyplinowanej pracy naznaczonego płcią ciała i jego ekspozycji. (Dobson 2015, 31) 31 $^{1}$

Upodmiotowienie kobiecego ciała jest też kluczową cechą hiperseksowności Peaches. W swojej sztuce tworzy obraz kobiety, która decyduje i rządzi; osoby zarówno pożądającej, jak i pożądanej; libertynki w czasach, kiedy hedonizm nie powinien już nikogo szokować, a jednak nadal to robi. Peaches nakazuje: „twarz w dół, fiut w górę, tak brzmi mój rozkaz” (Peaches 2015) ${ }^{32}$, by jednocześnie budować własną, autoironiczną i hiperseksowną tożsamość jako ta, „z podwójnymi A / myśląca o potrójnym X” (Peaches 2000)33.

${ }_{29}$ Przekład własny za: „You like it when I like you less / No caress, just undress / You like it when we play hardcore / The panty-war / You get pussy galore / You like it when I turn your back / Give you no slack / The slack attack / You like it when we leave parts on / When we're getting it on / On and on and on".

${ }^{30}$ Przekład własny za: „I. Am. The. One. Who. Will. Take. You”.

${ }^{31}$ Przekład własny za: „Powerful images of »active « rather than passive, desired and desiring female bodies are now common across mediascapes and in certain cultural scenes [...]. These are shifts that complicate the object/subject binary itself, as women are presented as, and invited toward agentic objectification or rather sexual subjectification that still involves, in short, a lot of disciplined gendered body work and display".

${ }^{32}$ Przekład własny za: „Face down, dick up, that's my command”.

${ }^{33}$ Przekład własny za: „Only double A / Thinking triple X”. 


\section{Rebel, Rebel. Hiperseksownością w patriarchat}

Dosadna i szeroko rozumiana konceptualizacja seksowności w wydaniu Peaches nosi oczywiste znamiona buntu przeciwko dominującemu systemowi moralności, który rości sobie prawo do mówienia nam co jest, a co nie jest ogólnie akceptowalne w zakresie kobiecej seksualności. Strategia taka ma swoją długą historię w dziejach myśli feministycznej; Greer zauważa: „Niektóre kobiety zawsze buntowały się przeciwko wyznaczonej im społecznie roli” (Greer 2001, 328). Jednak w tym przypadku ważnym punktem odniesienia staje się kontekst muzyki popularnej i kultury rocka. Peaches stwierdza: „Muzyka pop pełna jest słów i obrazów o tematyce seksualnej, ale płcie nie są w niej wyrażane w sposób równy. Mnie pociąga odwracanie tych form ekspresji tak, aby pasowały do mojego punktu widzenia” (Rosenblum 2013) ${ }^{34}$. Peaches nie jest pierwszą kobietą w świecie rocka, która stosuje taką strategię, i jest tego w pełni świadoma. Jest kolejną z tych postaci, które tworzą „,rockowy hałas jako podkład dla feministycznych tekstów i, tym samym, podważają tradycyjnie rozumianą kobiecość oraz problematyzują politykę genderową" (Kearney 2017, 207) ${ }^{35}$. Mówiąc bardziej precyzyjnie, Peaches w świadomy sposób stawia się w roli kontynuatorki dzieła kobiet wcześniej działających w ramach kultury muzyki rockowej, od samych początków tego gatunku, aż do punkowo-feministycznego ruchu Riot Grrrl. Dobson: „Przesunięcia w kierunku młodej, feministycznej siły, pewności siebie i wydolności zwykle zestawia się z hasłem »dziewczęcej siły«, frazy używanej przez zespoły ruchu Riot Grrrl we wczesnych latach dziewięćdziesiątych. Hasło to związane jest ze wzrostem świadomości seksualnej i płciowej przemocy; zasadza się na obalaniu norm kulturowych dotyczących kobiecej mody i eksponowania ciała" (Dobson 2015, 32) ${ }^{36}$.

Tym samym, bunt Peaches przeciwko patriarchatowi jest jednocześnie hołdem składanym przez nią tym buntowniczkom rocka, które ją poprzedziły. Doskonałym przykładem jest tu piosenka I don't give a fuck, która

34 Przekład własny za: „Pop music is full of sexual lyrics and images but not always expressed evenly through different genders. I enjoy twisting these expressions to fit my point of view". 35 Przekład własny za: "rock noise accompanied by feminist lyrics [and hence] challenge traditional femininity and trouble gender politics”.

${ }^{36}$ Przekład własny za: „Shifts toward young feminine strength, confidence, and capacity are positioned as accompanying »girl power «, as a phrase used by Riot Grrrl bands in the early 1990 s to raise awareness of sexual and gendered violence and subvert cultural norms of feminine fashion and bodily display". 
stanowi bezpośrednią reinterpretację klasycznego dla rocka hymnu feministycznego Bad reputation, stworzonego i zaśpiewanego przez Joan Jett. W słynnym utworze z 1980 roku Jett krytykuje zdominowany przez mężczyzn świat show biznesu oraz seksistowską politykę reprezentowaną przez przedstawicieli wytwórni płytowych:

Nie dbam o swoją reputację

To ty żyjesz w przeszłości

Idzie nowe pokolenie

Dziewczyna może robić co jej się podoba

I to właśnie robić zamierzam

Dobrze mi tylko wtedy kiedy mam ubaw

I kiedy nie muszę zadowalać innych

I w nosie mam swoją złą reputację.

$(\text { Jett 1981 })^{37}$

Podążając tropem Jett, która odrzuca stare i nieprzystające do rzeczywistości wzorce, Peaches idzie o krok dalej. W jej piosence pojawiają się wzięte bezpośrednio z oryginału fragmenty, które Kanadyjka uzupełnia wykrzyczanymi przez siebie słowami dobrze pokazującymi jej bezkompromisowość:

Wiesz co, chcę ci coś powiedzieć

I ty dobrze wiesz co, prawda?

Mam w nosie swoją reputację

Gówno mnie ona obchodzi!

Gówno mnie ona obchodzi!

Gówno!

$(\text { Peaches 2003) })^{38}$

Tą erupcją ordynarnego języka deklaruje się jako niebezpieczna jednostka, typ kobiecości określanej przez Germaine Greer mianem Okropnej Suki: „Okropna Suka to kobieta zabójcza, godna przeciwniczka wszechmocnego bohatera, na której i poprzez którą może demonstrować swoją władzę. Jest

${ }^{37}$ Przekład własny za: „I don’t give a damn ‘bout my reputation / You're living in the past, / It's a new generation / A girl can do what she wants to do / And that's what I'm gonna do... / An' I'm only doin' good when I'm havin' fun / An' I don't have to please no one / An' I don't give a damn 'bout my bad reputation”.

${ }^{38}$ Przekład własny za: „You know / I wanna tell you something / You know what? / I don’t give a damn about my reputation / I don't give a fuck! / I don't give a fuck! / I don't give a fuck!”. 
pożądliwa, chciwa, przebiegła, nieuczciwa i zawsze o dwa kroki do przodu" (Greer 2001, 208). Peaches jest właśnie taką współczesną, postfeministyczną wersją Okropnej Suki, kimś, kogo „tak naprawdę nie znasz” (Peaches 2003) ${ }^{39}$ (The inch), buntowniczką - ale nie urodzoną, tylko raczej powstałą w akcie autokreacji - która ma wiadomość do starego świata. W Light in places ostrzega: „Jestem wiecznym ikonoklastą / Przybyłam aby zniszczyć przeszłość / Mój gwiezdny orgazm przynosi spustoszenie/ Wstrząśnij systemem, a potem go przekrocz" (Peaches 2015) ${ }^{40}$.

Co jest niezwykłe w rebelii Peaches przeciwko patriarchalnemu sposobowi myślenia to to, iż przybiera ona formę hiperseksowności. W utworze Diddle my skittle śpiewa:

Myślisz, że jestem malutka

Że możesz na mnie grać jak na skrzypeczkach

Ale ja nie jestem taka krucha

Chodź, poturlaj moje kręgle

Bo jest tylko jedna brzoskwinka

$\mathrm{Z}$ dziurką w samym środku.

$(\text { Peaches 200o })^{41}$

Rebelia Peaches przybiera formę rozigranej, seksownej czynności: walcząc ze stereotypem pasywnej kobiety będącej seksualnym przedmiotem, Peaches w ironiczny sposób podkreśla swoją seksualność i prowokuje tradycyjnie seksistowskie męskie spojrzenie. Jednocześnie artystka zdaje się krytykować współczesny obraz pseudowyemancypowanych kobiet, które poprzez samą tylko ekspozycję siebie, jako jednostek seksownych - jedynie konsolidują status quo, akceptując męskie zasady seksualnej gry. Komentując świat gwiazd popu, Peaches zauważa: „Jennifer Lopez stale ocieka wodą, tak, że widać jej sutki i tyłek, ale to nic więcej jak tylko manipulowanie tanią sensacją. Jeśli macie prezentować taki wizerunek, to lepiej żebyście miały słowa piosenek na jego poparcie. Ja zawsze podaję to w sposób bezpośredni, ale z jakichś powodów jest to bardziej akceptowalne w przypadku

39 Przekład własny za: „you don’t really know”.

$4^{0}$ Przekład własny za: „I’m an everlasting iconoclast / I came to destroy the past / My stargasm makes the blast / Shake the system, then surpass".

${ }^{41}$ Przekład własny za: „You think I'm little / Wanna play me like a fiddle / I’m not so brittle / Come diddle my skittle / 'cause there's only one peach / With the hole in the middle". 
sztuk wizualnych, niż tekstu" (Carpenter 2003) ${ }^{42}$. Hiperseksowność w wydaniu Peaches jest zupełnie samoświadoma, a artystka odgrywa rolę seksualnej drapieżniczki, która stanowi zagrożenie dla mężczyzn i męskości. Jak wyznaje: „Podoba mi się typ niewinny / Jak jeleń w światłach samochodu” (Peaches 200o $)^{43}$, podkreślając tym samym swoją pozycję drapieżnika polującego na seksualną zwierzynę, gdyż „śliski fiut / jest tylko kolejną rybką w Atlantyku” (Peaches 2006) ${ }^{44}$. W utworze Fuck or kill pojawiają się natomiast słowa, które można uznać za kredo artystki: „Wolę pieprzyć kogo chcę / Niż zabijać kogo mi każą" (Peaches 2006) ${ }^{45}$.

\section{It's a woman's woman's woman's world. Obal stary system}

Kolejnym dowodem na trafność zestawienia kategorii hiperseksowności z transgresyjnymi strategiami Peaches jest fakt, że artystka świadomie i dosadnie wykracza poza tradycyjnie rozumianą heteroseksualność. Komentując kontrowersyjny tytuł swojej drugiej płyty - Fatherfucker - stwierdza: „Nieustannie mówię o równości. Jeśli wolno nam mówić »motherfucker «, to dlaczego nie powiedzieć również »fatherfucker «; jeśli mówimy »potrząśnij cyckami i tyłkiem«, to dlaczego nie powiedzieć »potrząśnij fiutem «" (Carpenter 2003 ${ }^{46}$. Wypowiedź ta to zdecydowanie więcej, niż tylko chęć szokowania. Artystka wyjaśnia: „Jest czymś niedorzecznym to, że odrzucamy nasze ciała, jednocześnie zgadzając się na warunki i wartości rodzinne, które w gruncie rzeczy są niczym więcej niż patriarchalnymi wartościami rodzinnymi” (Azzopardi 2015) ${ }^{47}$. Jej cel to obalenie przestarzałej struktury, ponieważ tylko wtedy możliwe będzie uwolnienie pełnego spektrum ludzkich

${ }_{42}$ Przekład własny za: „Jennifer Lopez [is] always getting wet and you see her nipples and ass, but it's just totally manipulative sensationalism. If you're gonna give out images like that, you'd better have the lyrics to back it up. I give it directly, but for some reason it's acceptable to do it visually, but not lyrically”.

${ }^{43}$ Przekład własny za: „I like the innocent type / Deer in the headlight”.

${ }^{44}$ Przekład własny za: „slippery dick / It’s just a fish in the Atlantic”.

45 Przekład własny za: „I'd rather fuck who I want / than kill who I’m told to”.

${ }^{46}$ Przekład własny za: „All I’m talking about is equality. If we're saying motherfucker, let's say fatherfucker, if we're saying shake your tits and shake your asses, let's say shake your dicks".

${ }^{47}$ Przekład własny za: „It’s ridiculous how we deny our bodies and have all these stipulations and family values, which are just patriarchal family values”. 
seksualności. Dlatego deklaracji Peaches nie należy traktować tylko jako prowokacji, ale należy je również postrzegać w kategoriach postulowanej równości w sferze doświadczeń seksualnych.

Strategie Peaches dotyczące doświadczenia seksualnego zakładają przekraczanie zarówno normatywnej heteroseksualności, jak i moralnej hipokryzji często za nią się kryjącej. O tej ostatniej Rubin mówiła tak:

Moralność demokratyczna powinna osądzać akty seksualne według sposo$\mathrm{bu}, \mathrm{w}$ jaki partnerzy traktują się nawzajem, poziomu wzajemnej rozwagi, obecności lub braku przymusu oraz ilości i jakości dostarczanej przyjemności. To, czy zachowania seksualne są homo- czy heteroseksualne, w parach czy w grupach, nago czy w bieliźnie, za pieniądze czy za darmo, z udziałem materiałów wideo czy bez nich, nie powinno stanowić przedmiotu zainteresowanie etyki. (Rubin 2007,153$)^{4^{8}}$

Idąc tym tropem, Peaches zdaje się traktować męską homoseksualność jako punkt wyjścia w swojej walce z patriarchalną nierównością w sferze seksu. Dodatkowo walkę tę toczy na terytorium muzyki rockowej, jak już zauważyliśmy, tradycyjnie zdominowanej przez mężczyzn i z gruntu heteroseksualnej. Na przykład, w piosence Back it up, baby zwraca się do męskiego odbiorcy, aby ten w akcie seksualnym przyjął rolę bierną i otworzył się na przyjemności penetracji: „Słodkie pośladki, dziś będę waszą armatką / Czy nie wiesz, że chłopcom tak jest ponoć lepiej” (Peaches 2003) ${ }^{49}$. Podważając to erotyczne tabu, Peaches zwraca uwagę na długą tradycję opisywania takich praktyk seksualnych tekstach rockowych. Problem polega na tym, że jak dotąd w kulturze rocka seks analny prezentowany był z typowo męskiej i heteroseksualnej perspektywy. Wokalistka komentuje: „Artyści bluesowi i hip-hopowi ciągle powtarzają »I'm a back door man«, »Back it up, baby«, czy »Back that ass up «" (Carpenter 2003) $)^{50}$. Tym samym wyraźnie wskazuje na brak równości w tej sferze: to, co jest tradycyjnie akceptowane, kiedy

${ }^{48}$ Przekład własny za: „A democratic morality should judge sexual acts by the way partners treat one another, the level of mutual consideration, the presence or absence of coercion, and quantity and quality of the pleasures they provide. Whether sex acts are gay or straight, coupled or in groups, naked or in underwear, commercial or free, with or without video, should not be ethical concerns”.

49 Przekład własny za: „Sweet buns, let me be your gun / Don’t you know it’s supposed to feel better for boys?".

${ }^{50}$ Przekład własny za: „Blues and hip-hop artists always say »I’m a back door man«, »Back it up, baby«, »Back that ass up«”. 
śpiewają o tym mężczyźni, staje się wulgarne i zupełnie nieakceptowalne, kiedy jest wyrażane przez kobiety. Realizując postulat Dobson, zakładający, że „pożądanie jest prowokowane i mile widziane, a stabilność jest odrzucana" (Dobson 2015, 65) ${ }^{51}$, Peaches z pełną świadomością przekracza niejedną granicę dotyczącą patriarchalnej moralności. W Dick in the air śpiewa:

Mamy już dość rąk wyciągniętych w górę

I potrząsania tyłkami jakby to nic nie znaczyło

Potrząsamy cyckami od lat

Może więc czas się zamienić pozycjami

Bez zahamowań, bez lęków.

$(\text { Peaches 2015) })^{52}$

Otwartość i bezpośredniość hiperseksowności pozwala jej na zadawanie fundamentalnych pytań dotyczących dystrybucji władzy pomiędzy kobietami, a mężczyznami. Choćby takich jak to: „Jesteś gotowy? / Gotowy na przejęcie?” (Peaches 2006) 53 .

\section{$* * *$}

Komentując programową męskość muzyki rockowej, Kearney stwierdza:

Głośność, przestery i hałas od dawna konotują męskość poprzez sugerowanie władzy, kontroli i agresji. $Z$ drugiej strony ciszę i łagodność od lat uznaje się za kobiece, z powodu zasugerowanych w nich bierności i komfortu. Stąd, podczas gdy mężczyźni automatycznie potwierdzają swoją męskość, grając rocka, dziewczyny i kobiety związane z muzyką rockową - czy to jako jej wykonawczynie, czy też odbiorczynie - dokonują niezbędnej transgresji wobec wiekowych norm płciowych, określających dźwięk i muzykę. Niektóre kobiece zespoły rockowe robią hałas w geście jawnie feministycznym, podkreślając swoją opozycję wobec patriarchatu i mizoginii właśnie poprzez występy pełne głośnej i przesterowanej muzyki. (Kearney 2017, $206-207)^{54}$

${ }^{51}$ Przekład własny za: „desire is provoked and invited, but stability is denied”.

${ }^{52}$ Przekład własny za: „We're sick of hands in the air / And shake our asses like we don't care / We've been shaking our tits for years / So let's switch positions, no inhibitions, fears".

${ }^{53}$ Przekład własny za: „Are you ready? / Ready for the takeover?”.

54 Przekład własny za: „Loudness, distortion, and noise have long connoted masculinity through their suggestions of power, control, mastery, and aggressiveness. In contrast, 
Wydaje się, że zogniskowane na hiperseksowności działania Peaches idealnie wpisują się w tak zakreśloną politykę. Peaches wykoślawia stare reprezentacje seksualności, aby obnażyć ich nieadekwatność i sztuczność. W swoich naładowanych seksualnością performance'ach jest głośna i agresywna po to, żeby nie dało się ich i jej zignorować. Ciągle przekracza normy, ponieważ wie, że hiperseksowność musi być stale płynna, stale w ruchu. Tylko wtedy jej buntowniczy gest może mieć znaczenie.

quietness and softness have long been figured as feminine because of their suggestions of passivity and comfort. Thus, while male musicians automatically affirm their masculinity by playing rock, girls and women who become involved in rock music, either as performers or consumers, necessarily transgress age-old gender norms associated with sound and music. Some women-centered rock bands have used their ability to create noise as a feminist gesture, foregrounding their opposition to patriarchy and misogyny through their performance of loud, distorted music". 


\section{Bibliografia}

Azzopardi, Chris. 2015. „Peaches talks childhood trans friend, sex in pop music, vaginas and how Nicki Minaj »slays all these guys «". PrideSource. Dostęp: 10.04.2019. https://pridesource.com/article/73390-2/.

Dobson, Amy Shield. 2015. Postfeminist digital cultures. femininity, social media, and self-representation. New York: Palgrave Macmillan.

Carpenter, Lorraine. 2003. „Profane Peaches”. Exclaim.ca. Dostęp: 10.04.2019. http://exclaim.ca/music/article/profane_peaches/.

Greer, Germaine. 2001. Kobiecy eunuch. Tłum. Joanna Gołyś i Bożena Umińska. Poznań: Dom Wydawniczy Rebis.

Jarniewicz, Jerzy. 2019. „Yoko Ono. Spacer po cienkiej tafli lodu”. [w:] J. Jarniewicz, Bunt wizjonerów, 148-163. Kraków: Wydawnictwo Znak.

Kearney, Mary Celeste. 2017. Gender and rock. Oxford: Oxford University Press.

Mullen, Kathleen. 2015. „Peaches”. TheCanadianEncyclopedia.ca. Dostęp: 10.04.2019. https://www.thecanadianencyclopedia.ca/en/article/ peaches.

Rosenblum, Sarah Terez. 2013. „Peaches on doing herself and gender ambiguity". AfterEllen.com. Dostęp: 10.04.2019. https://www.afterellen. com/general-news/106715-peaches-on-doing-herself-and-gender-am biguity.

Rubin, Gayle S. 2007. „Thinking sex: notes for a radical theory of the politics of sexuality". [w:] Culture, Society and Sexuality. A Reader, red. Richard Parker i Peter Aggleton, 143-178. London: Routledge. Dostęp: 10.04.2019. http://sites.middlebury.edu/sexandsociety/files/ 2015/01/Rubin-Thinking-Sex.pdf.

\section{Dyskografia}

Jett, Joan. 1981. Bad reputation. Boardwalk Records.

Peaches. 2000. The teaches of Peaches, Kitty-Yo.

2003. Fatherfucker, XL Recordings.

2006. Impeach my bush, XL Recordings.

2009. I feel cream, XL Recordings.

2015. Rub, I U She Music .

Simone, Nina. 1966. Wild is the wind. Philips Records. 


\title{
Abstract, keywords, about the author
}

\begin{abstract}
Rebellious Hypersexiness: Dismantling of Male Popculture according to Peaches

Peaches is one of the most controversial popcultural icons of the twenty-first century. Born as Merrill Beth Nisker, Peaches is a Canadian artist who deals in her arts - mostly centered on electro rock music - with the issues of sexual freedom, and the hypocrisy of the contemporary power structures that still govern the relations between people, making the shade of patriarchy present. In her artistic activates - predominantly, but not exclusively, the lyrics to her songs - she performs a number of sexual transgressions that provoke questions about equality, identity, and liberty. She subverts the old, hypocritical system of values employing an explicitly shocking and direct attitude to sexualities that can be called hypersexiness. This article attempts to present Peaches' uncompromising artistic attitude and is an attempt to read it through the aforementioned category of hypersexiness.
\end{abstract}

Keywords: Peaches, hypersexiness, rock music, sexualities, patriarchy, transgression

Sławomir KuźnICKI, doctor of the humanities in the field of literary studies; an Assistant Professor at the Institute of Literary Studies, University of Opole; the author of Margaret Atwood's Dystopian Fiction: Fire Is Being Eaten (2017), as well as numerous other articles in the academic fields of utopian, dystopian, speculative and science fiction, as well as the literary and cultural contexts of rock music; the editor in "Explorations: A Journal of Language and Literature"; a poet with four volume of poetry (recently: Contours, 2018).

E-MAIL: slavekkk@wp.pl 